\title{
Social Support as Moderator of Knowledge about Infant Development in Adolescent Mothers ${ }^{1}$
}

\author{
Eva Diniz ${ }^{2}$ \\ Universidade Federal do Rio Grande do \\ Sul, Porto Alegre-RS, \\ Brazil \\ Luana de Souza dos Santos \\ Universidade Federal de Ciências da \\ Saúde de Porto Alegre, Porto Alegre-RS, \\ Brazil
}

\author{
Silvia Helena Koller \\ North-West University Vanderbijlpark, \\ South Africa \\ Universidade Federal do Rio Grande \\ do Sul, Porto Alegre-RS, Brazil
}

\begin{abstract}
Knowledge about child development (KIDI) is an important dimension of infant care. Although it has been discussed that adolescent mothers, compared with adult mothers, reveal lower average of KIDI, little is known about variables associated with it, as well as its variation over time. We aimed to investigate longitudinally KIDI during infant's first year and its interaction with maternal behaviors, social support/ postpartum depression. KIDI was evaluated according to its corrected and wrong answers for each dimension of infant's development. Participants were originally 49 adolescents (16.49 years; $S D=1.58)$. They answered to KIDI, social support, and maternal depression at pregnancy, $3(n=41), 6(n=39)$, and 12 months postpartum $(n=35)$. Results revealed that KIDI increased during the first year postpartum, qualified with an interaction with social support. Social support plays an important role to increase KIDI, particularly within adolescent mothers living in vulnerable backgrounds.
\end{abstract}

Keywords: childhood development, adolescent mothers, support groups, postpartum depression

\section{Apoio Social como Moderador do Conhecimento Infantil em Mães Adolescentes}

\begin{abstract}
Resumo: O conhecimento sobre desenvolvimento infantil (CDI) é importante nos cuidados da criança. Embora estudos revelem que mães adolescentes tendem a ter um CDI inferior às adultas, desconhecem-se variáveis associadas à sua variação no decorrer do tempo. $\mathrm{O}$ objetivo foi investigar longitudinalmente o CDI em uma amostra de mães adolescentes e sua associação com qualidade do comportamento materno, apoio social e depressão pós-parto. O CDI foi avaliado em termos de acertos e erros nas respostas a diferentes dimensões do desenvolvimento infantil. Originalmente participaram do estudo 49 adolescentes (16.49 anos; $D P=1.58)$ que responderam ao CDI, apoio social e depressão pós-parto na gravidez, três $(n=41)$, seis $(n=39)$ e 12 meses pós-parto $(n=35)$. Resultados revelaram que o CDI melhorou durante o primeiro ano de vida, qualificado por uma interação com apoio social. $O$ apoio social pode trazer informações às quais, em geral, as mães adolescentes têm menos acesso, particularmente em mães adolescentes que vivem em contextos de vulnerabilidade.
\end{abstract}

Palavras-chave: desenvolvimento infantil, mães adolescentes, grupos de apoio, depressão pós-parto

\section{Apoyo Social como Moderador del Conocimiento sobre el Desarrollo Infantil en Madres Adolescentes}

\begin{abstract}
Resumen: El conocimiento sobre el desarrollo infantil (CDI) es una dimensión importante en el cuidado de niños. Aunque los estudios muestran que las madres adolescentes tienden a tener CDI inferior a las adultas, se sabe poco sobre las variables asociadas y su variación en el tiempo. Investigamos longitudinalmente la modificación del CDI en el primer año de vida de niños y la interacción del CDI con calidad de cuidado, apoyo social o depresión posparto. Evaluamos el CDI según los aciertos y errores para cada dimensión del desarrollo infantil. Originalmente participaron 49 adolescentes (16.49 anos; $D E=1.58)$ que respondieron al CDI, apoyo social y depresión posparto durante el embarazo, tres $(n=41)$, seis $(n=39)$ y doce meses $(n=35)$ posparto. Los resultados indicaron que el CDI mejoró durante el primer año de vida y fue calificado por una interacción con apoyo social. El apoyo social tiene papel importante en el aumento del CDI, particularmente para las madres adolescentes viviendo en situación de vulnerabilidad.
\end{abstract}

Palabras clave: desarrollo infantil, madres adolescentes, grupos de autoayuda, depresión post-parto

Experiencing maternity during adolescence involves aspects that differentiate it from other forms of parenting (Jahromi, Guimond, Umaña-Taylor, Updegraff, \& Toomey, 2014). The context in which psychosocial vulnerability tends to occur represents the greatest risk for the healthy development of mothers and babies (Breheny \& Stephens,

\footnotetext{
${ }^{1}$ Support: CNPq, Processo 506368/2013-0

${ }^{2}$ Correspondence address:

Rua Ramiro Barcelos, 2600, sala 104, 90035-003 Porto Alegre-RS, Brasil.
}

2007; World Health Organization [WHO], 2011). In Brazil, 67.2/1,000 births occur among adolescents aged between 1519 years old (Instituto Brasileiro de Geografia e Estatística [IBGE], 2012). Poor socioeconomic conditions, in addition to the emotional immaturity of mothers, are the main challenges to overcome (WHO, 2011). Hence, characteristics associated with adolescent motherhood deserve to be investigated (Jahromi et al., 2014), especially in the Brazilian context.

Cognitions regarding child development influence the type of care delivered to the babies and the interaction 
established between mother and child (Bornstein, Cote, Haynes, Hahn, \& Park, 2010; Ribas, Seidl de Moura, \& Bornstein, 2003; Sanders, 2012). Cognitions are composed of beliefs, conceptions, values, expectations and knowledge on child development, organized into four dimensions: standards, principles, parenting, and health (Sanders, 2012). The importance of cognitions in child development is that they are associated with the care provided to children. For instance, if a mother believes that her baby is unable to hear at birth, she will not talk to him/her. Such a misbelief will modulate the interaction established with the baby, harming her/his development. On the other hand, if there are inflated expectations regarding a child's development, for instance that a 12-month old child should have sphincter control, this may lead to inappropriate strategies and cause frustration (Huang, Caughy, Genevro, \& Miller, 2005). Therefore, cognitions influence the quality of a mother's behavior. Mothers with greater knowledge of child development tend to better organize their environment, adapting it to the child's developmental needs, and respond in a more sensible manner to the child's behavior (Ribas et al., 2003; Tamis-LeMonda, Shannon, \& Spellmann, 2002). This aspect is particularly important among adolescent mothers, who tend to be more intrusive in relation to their children (Lanzi, Bert, Jacobs, \& Centers for the Prevention of Child Neglect, 2009; TamisLeMonda et al., 2002).

Maternal cognitions, are in general, strongly associated with maternal behavior, since they regulate the care delivered to children. Children whose parents attain greater knowledge of child development reveal improved cognitive and behavioral adjustment (Jahromi et al., 2014; Winter, Morwaskw, \& Sanders, 2012). Cognitions influence the quality of interaction between parents and children, moderating stimuli that parents provide to children, as well as their expectations (Bornstein et al., 2010). Therefore, parents with a greater ability to identify a child's needs provide appropriate responses and are less likely to neglect or mistreat their children.

Most studies addressing maternal cognitions, however, are developed with middle-class American mothers, so that it is necessary to investigate knowledge of child development among other populations and socioeconomic levels (Bornstein et al., 2010; Tamis-LeMonda et al., 2002), namely, adolescent mothers (Jahromi et al., 2014). The few studies addressing adolescent mothers (generally of a low socioeconomic status) tend to compare them to middle-class adult mothers, which hinders assessment of their real level of knowledge or the effect of such knowledge on child development since it may be conditioned on socioeconomic status (Bornstein et al., 2010; Luo \& Tamis-LeMonda, 2015).

One study revealed that adolescent mothers have greater knowledge of verbal, cognitive and motor development compared to their knowledge of social development (TamisLemonda et al., 2002). Additionally, adolescent mothers have accurate knowledge concerning the order in which milestones are expected to be achieved, but do not know when milestones should take place, that is, the age at which children should achieve certain milestones. In this sense, it is important to investigate contextual aspects that strengthen cognitions of child development (Jahromi et al., 2014; Tamis-LeMonda et al., 2002). Even though social support stands out as a variable associated with maternal cognitions (Jahromi et al., 2014), this relationship remains unclear.

Social support is an essential variable for motherhood, especially during adolescence (Devereux, Weigel, BallardReisch, Leigh, \& Cahoon, 2009). Social support is defined as a set of formal and informal relationships that provide emotional, material and/or instrumental help when someone needs to cope with situations that cause some type of emotional tension (Griep, Chor, Faerstein, \& Lopes, 2003). It is a multidimensional construct related to one's perception of the social world, resources available, and how protected one feels when facing situations of risk. A lack of social support is identified as one of the greatest difficulties adolescents face during pregnancy or parenting (Lanzi et al., 2009).

Social support enables a pregnant adolescent to discuss doubts/difficulties faced in the care provided to the baby, improving the adolescent's level of knowledge (Jahromi et al., 2014). Additionally, it is known that lack of social support is associated with greater levels of stress and postpartum depression (Devereux et al., 2009; Lanzi et al., 2009). Little is known, however, about the relationship between maternal level of knowledge, on the one hand, and child development and social support, on the other (Fuligni et al., 2013; O'Callaghan, Borkowski, Whitman, Maxwell, \& Keogh, 1999). This gap in knowledge is even greater among adolescent mothers, especially those living in a situation of psychosocial vulnerability (Jahromi et al., 2014). This is relevant information to deepen knowledge and devise interventions specific for this population.

Maternal depression has also been identified as one of the most evident problems faced during an adolescent pregnancy, as its prevalence is higher than in adult mothers (Petterson \& Albers, 2001). Poverty and lack of social support are the main causes of increased maternal depression among adolescents (Bornstein, 2013; Petterson \& Albers, 2001). Depressive mothers tend to be less responsive to their babies and have more difficulty identifying their needs (Brown, Harris, Woods, Buman, \& Cox, 2012).

This longitudinal study's general objective was to investigate knowledge of child development (KCD) in a sample of adolescent mothers and its association with the quality of maternal behavior, social support and post-partum depression. The specific objectives were to investigate: (1) the KCD's dimensions whose answers received more correct answers and those with more incorrect answers; (2) whether KCD is modified over the child's first year of life; (3) association between the quality of maternal behavior and changes in KCD over time and, if such an association exists, verify its moderator effect on association with social support and/or post-partum depression; and (4) whether social support and/or maternal depression moderates changes in one's level of knowledge concerning child development. 


\section{Method}

\section{Participants}

Forty-nine adolescents participated in this longitudinal study from pregnancy up to 12 months after delivery. The mothers were 16.49 years old $(S D=1.58)$, on average, on the date of their first interview and $65.3 \%$ reported living with or being married to the baby's father (see Table 1 for further information on the participants). Participation in the study was conditioned on the following inclusion criteria: (1) age between 14-19 years old; (2) being in the pregnancy's second or third quarter; (3) considering oneself the baby's primary caregiver. The exclusion criteria were: (1) self-reporting of drug and/or alcohol consumption; (2) having a preterm baby (gestational age less than 37 weeks or birth weight below $2,500 \mathrm{gr}$ ); or (3) reporting of anomaly or developmental impairment.

Eight out of the 49 participants in the original sample withdrew from the study, four moved out of the state, and two children were removed from their mothers' care, which impeded their participation. The final sample included 35 participants. None of the children were born preterm or with developmental problems. The average birth weight was 3,175 gr ( $S D=.45 \mathrm{gr})$. In terms of post-partum depression, $42.9 \%$ of the mothers were above the cut-off point during pregnancy; $61.0 \%$ were above the cut-off point at 3 months; $33.3 \%$ at 6 months; and $48.5 \% 12$ months after delivery.

Table 1

Demographic Information about Adolescent Mothers $(N=49)^{1}$

\begin{tabular}{lr}
\hline & Adolescent $\%(n)$ \\
\hline Current status ${ }^{2}$ & \\
"At home" & $53.10(26)$ \\
Studying & $42.9(21)$ \\
Working & $12.2(6)$ \\
Years attending school $(M ; S D)$ & $7.02(2.35)$ \\
Years they left school school (months; & $4(0-13)$ \\
$M d n ; I Q R)^{3}$ & Total \%(n) \\
\hline & $65.3(32)$ \\
\hline Married/Living together & $5(0 ; 12)$ \\
Time living together (months; $M d n ; I Q R)^{3}$ & $890.37(S D=258.27)$ \\
\hline
\end{tabular}

${ }^{1}$ Information regarding T1; ${ }^{2}$ Multiple answer; ${ }^{3}$ Median (Md) and Interquartile Range (IQR) were used to non-normal data.

\section{Instruments}

Knowledge of Infant Development Inventory - KIDI (Ribas et al., 2003). The instrument assesses parental knowledge of child development with 75 questions. The items are organized into four dimensions: (1) Standards and development milestones, composed of 32 items that describe the typical period when children become able to perform a given skill; (2) Principles, composed of 17 questions on developmental processes; (3) Parenting, with 14 items assessing beliefs regarding parental attitudes; and (4) Health and safety, with 12 questions on accident prevention, food, health and hygiene. The instrument includes three modalities of answers. First, the respondent is supposed to check the option that seems accurate (I agree; I disagree; or I am not sure) in regard to certain statements (e.g.: "The mother (or father) needs only to feed, clean and dress the baby for him/ her to be well"). In the second part, the respondent is asked to choose one option (I agree; older; younger; I am not sure) that characterizes when a given skills is attained (e.g.: "Most babies can sit on the floor at the age of 7 months and do not fall over"). Finally, the respondent is supposed to choose the correct option for a given statement concerning parental practices (e.g.: "The best way to deal with a one-year-old child who plays in the living room where things can break is: (a) to keep him/her in a playpen and keep everything out of reach; (b) Slap the baby's hand every time s/he touches something; (c) Say "No!" to the child and expect her/him to obey; (d) Put things out of reach until the child becomes older; and (e) I am not sure. The Brazilian version obtained a Cronbach's alpha of .81. In this study, the following internal consistent coefficients were obtained: .87 (during pregnancy); .74; .68; and .65 (at three, six and 12 months after birth, respectively).

Social Support Scale (Griep et al., 2005). This scale is composed of 19 items addressing the frequency social support is received, on a five-point Likert scale, in which one (1) corresponds to "not often" and five (5) corresponds to "very often" (e.g.: "With what frequency is have someone available to help if you become sick?"; "With what frequency do you have someone to help you in a situation of crisis?"). In the study in which the scale was validated for the Brazilian context, the scale obtained an internal consistency coefficient of .81. In this study, the following coefficients were obtained: .87 during pregnancy; .93 at three months; .94 at six months; and .95 at 12 months after birth.

Edinburg Postnatal Depression Scale - EPDS (Santos, Martins, \& Pasquali, 1999). The EPDS is composed of 10 items for response on a four-point Likert scale, in which zero (0) corresponds to the absence of symptoms and three (3) corresponds to symptoms of longer duration and greater intensity. The items are totaled into a single score, in which the highest score corresponds to more intense depressive symptoms. The cut-off point in the Brazilian population used to establish a diagnosis of depression is 10 . In the Brazilian validation study, the scale obtained a Cronbach's alpha of .86. In this study, the following coefficients were found: .74 (during pregnancy); .81 (at 3 months); .80 (at 6 months); and .85 (12 months after birth).

\section{Procedure}

Data Collection. The participants took part in a longitudinal study from pregnancy up to 12 months after birth. There were four meetings: during pregnancy (T1); three (T2), six (T3), and 12 months after birth (T4). The participants were invited to take part in the study during pregnancy when attending public obstetrical centers in the city of Porto Alegre, RS, Brazil and in places where they attended prenatal care. After consenting to participate in the study, an interview was 
scheduled and a free and informed consent form was signed either by the participant herself or, when the mother was a minor, by her legal guardian.

The interview during the pregnancy was conducted on the premises of the obstetrical center in which prenatal care was provided. The interviews after the babies were born were conducted in the participants' homes, that is, at three, six and 12 months after delivery, by previously trained research assistants. The interviews were scheduled at times the babies were expected to be awake. Each participant was informed about the research protocol and instructed to act with the baby as she normally would. The participants were also informed they could attend to the baby whenever necessary and could interrupt the interview if it would be inconvenient not to do so.

During meetings, the participants were observed when they freely interacted with their babies and responded to a semi-structured interview addressing pregnancy and child development, about the participants' relationships with their partners/families, and occupations they had at the time of pregnancy. Afterwards, they answered the scales regarding social support, depression, and knowledge concerning child development. The entire procedure was filmed with the prior consent of the participants.

Data analysis. Qualitative: Coding maternal behavior (further details regarding the procedure can be found in Diniz, Volling \& Koller, 2014; Diniz, DeSousa, Volling, \& Koller, 2016). Each mother-infant pair was filmed during the interview based on the double-task paradigm (Smith \& Pederson, 1988) and behaviors were coded at 15-second intervals (Fouts, Roopnarine, Lamb, \& Evans, 2012; Isabella, 1988). Observations were standardized due to the different durations of each interview. A composite dimension of "positive maternal behavior" was created. Of the total interviews, 30\% were selected and coded by two independent judges (previously trained) and an inter-judge agreement above 0.90 was found for each point in time.

Quantitative. Data were analyzed with SPSS, version 18. The results are presented in two different sections. The first addresses KIDI dimensions, in which more hits and misses were obtained according to the percentage of correct answers obtained with paired t-tests and analysis of proportion. In the second section, a multivariate analysis of variance of repetitive measures was performed to investigate knowledge concerning child development over time and moderation of maternal behavior, social support and/or maternal depression.

\section{Ethical Considerations}

The study was approved by the Institutional Review Board at the Psychology Institute of the university of affiliation of both authors (protocol 19841).

\section{Results}

Characterization of Knowledge of Infant Development The total number of correct answers for each of the four KIDI dimensions was verified (Parenting, Health, Standards, and
Principles). On average, the participants correctly answered 38.95 out of 75 questions $(S D=6.83$; $\operatorname{Max} .=56$; Min. $=16)$ at $\mathrm{T} 1 ; 44.23(S D=6.64$; Max. $=56$; Min. $=28)$ at T2; 45.33 $(S D=6.72$; Max. $=56$; Min. $=27)$ at T3; and 46.38 at $\mathrm{T} 4$ $(S D=7.23$; Max. =58; Min. =30). Because each of the four dimensions is composed of a different number of questions, the total number of hits and misses was weighted for each of these dimensions. A multivariate analysis of variance for repeated measures was performed (points in time: T1; T2; T3; and T4) x 4 (KIDI dimensions: Parenting, Health, Standards, and Principles) to verify whether the total number of correct answers per dimension changed over time. Effect sizes (partial eta-square; $\eta_{\mathrm{p}}^{2}$ ) are reported for each model. $\eta^{2}$ describes the variance of the sample in values between: .01.03 ; .06-.09; and > .14, which respectively correspond to low, moderate or high effect (Cohen, 1988).

A main effect of the total of correct answers per KIDI dimension was found, Wilks' lambda $=.48, F(3,26)=10.8, p$ $<.01, \eta_{\mathrm{p}}^{2}=.52$ and for time, Wilks' lambda $=.32, F(3,26)=$ $20.02, p<.01, \eta_{\mathrm{p}}^{2}=.68$; though without interaction between KIDI dimensions and time, Wilks' lambda $=.76, F(3,18)=$ .71, ns. The Post hoc text with Bonferroni correction for KIDI dimensions revealed that only Standards significantly differed from the remaining dimensions, with a mean of correct answers lower than that of Parenting (difference of means [DM]: -.07; $S E=.02 ; p<.05)$; Health (DM: $-.08 ; S E=.02 ; p<.01)$ and Principles (DM: -.10; $S E=.02 ; p<.001)$. The effect of time on correct answers was significant from T1 to T2 (DM: -.13; $S E=$ $.02 ; p<.001$ ); from T1 to T3 (DM: $-.12 ; S E=.02 ; p<.001)$; and from T1 to T4 (DM: -.08; $S E=.02 ; p<.001)$.

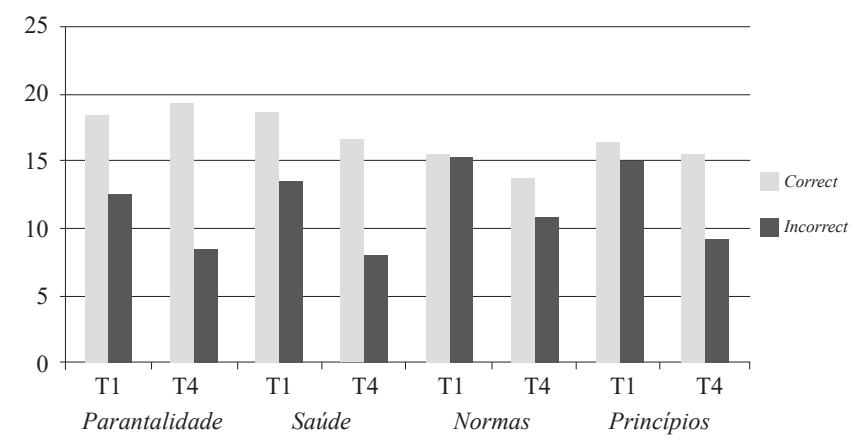

Figure 1. Total of correct and incorrect answers depending on KIDI dimensions in $\mathrm{T} 1$ and $\mathrm{T} 4$.

Considering the significant difference of $\mathrm{T} 1$ in comparison to the remaining times, we verified which questions the participants found easier or more difficult at T1 and T4 (Figure 1). Question 2 ("A baby needs to visit a physician monthly, in the first year of life") at T1 was the question that was more frequently answered correctly, while question 62 ("A 4-month-old baby lying on his/her stomach is able to raise his/her head") was the one more frequently answered incorrectly at T1. Answers to these questions remained the same at T4. When, however, we verified differences in misses from $\mathrm{T} 1$ to $\mathrm{T} 4$, the questions for which wrong answers decreased were: "The mother (or 
father) only needs to feed, clean and dress the baby for him/ her to be well" (Question 1) and "The best way to lower a baby's temperature (correct option; question 75)".

\section{Investigation of Level of Knowledge Over Time and the Moderator Effect of Social Support and Maternal Depression}

The main objective was to analyze whether the total number of correct answers to the Knowledge of Infant Development Inventory (KIDI) changed at the different points in time (pregnancy [T1]; 3 [T2]; 6 [T3] and at 12 months after birth [T4]) and whether the quality of maternal behavior, level (high vs. low) of social support and/or maternal depression moderated this association in a repeated measures analysis of variance.

In order to use social support as a moderator, we first verified whether it differed over the four different points in time. Since no significant difference was found in any of the four different points in time (Wilks Lambda $=.87, F(3,31)=$ $2.32, n s)$, social support was transformed into a dichotomous variable in order to obtain high and low levels of social support. Transformation was performed using the median of each of the variables, summing up one standard deviation (high social support) or decreasing the median standard deviation (low social support). Likewise, no significant differences were found at the four different points in time for maternal depression [Wilks Lambda $=.96, F(3,29)=.42$, $n s]$, so that the same procedure was adopted, as well as for maternal behavior, which also did not significantly differ over time (Wilks Lambda $=.69, F(3,15)=3.26, n s$ )

A multivariate analysis of variance for the repeated measures model was created (times assessed: T1; T2; T3; T4) $\mathrm{x} 2$ (high $v s$. low quality of maternal behavior) to investigate whether the total number of correct answers changed over time and, if it changed, whether it was qualified by an interaction with social support. A main effect of time was found, Wilks' lambda $=.44, F(3,18)=7.78, p<.01, \eta_{\mathrm{p}}^{2}=.96$, but it was not associated with the quality of maternal behavior, Wilks' lambda $=.98, F(3,18)=.12$, $n s$.

Afterwards, we verified whether knowledge of infant development was moderated by the level of social support. A multivariate analysis of variance for the repeated measures model (T1; T2; T3; T4) x 2 (high vs. low social support) was created. A main effect of time was found, Wilks'lambda $=.44$, $F(3,26)=10.85, p<.001, \mathrm{\eta}_{\mathrm{p}}^{2}=.56$. A high effect power was found, which explained $56 \%$ of the total number of correct answers over the four points in time. Note that the main effect was qualified by interaction with social support, Wilks' lambda $=.67, F(3,26)=4.30, p<.05, \eta_{p}^{2}=.33$. This value corresponds to a high effect of the influence of social support level on the total number of correct answers at each of the points in time. We verified that the total number of correct answers was significantly greater in the group of mothers with high social support (see Figure 2).

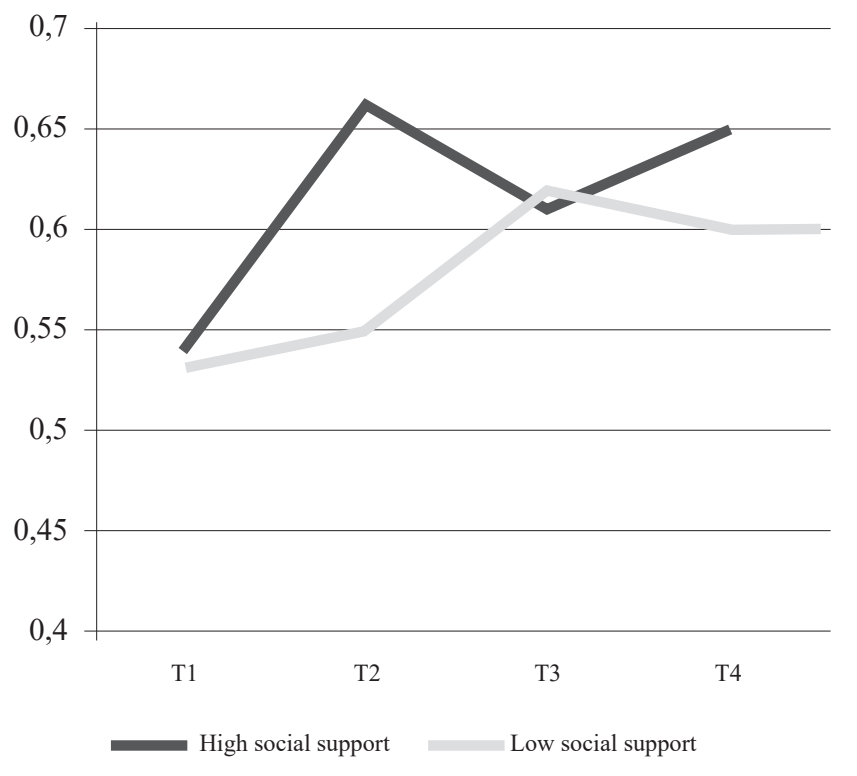

Figure 2. Average of correct answers according to social support.

The result of the paired t-test revealed that the effect of time was significant in the group with high social support from: $\mathrm{T} 1$ to $\mathrm{T} 2, t(16)=-3.07, p<.01$; from $\mathrm{T} 1$ to $\mathrm{T} 3, t(16)=$ $-2.40, p<.05$; from $\mathrm{T} 1$ to $\mathrm{T} 4, t(15)=-5.25, p<.001$; and from $\mathrm{T} 3$ to $\mathrm{T} 4, t(15)=-2.57, p<.05$. In turn, the paired $t$-test was significant for the group of low social support in the following time periods: T1 (pregnancy) to T3 (six months after birth), $t(16)=-3.84, p<.01$; T1 to T4 (12 months after birth), $t(15)=$ $-3.44, p<.01$; and from T2 (3 months after birth) to T3, $t(14)$ $=-2.56, p<.05$.

To verify whether the number of correct answers to the KIDI was qualified by interaction with maternal depression, a multivariate analysis of variance for the repeated measures model was created (points in time) $\mathrm{x} 2$ (maternal depression $v$. no depression) of the repeated measures of analysis of variance in the first factor. No interaction was found between effect of time and the presence of depression, Wilks' lambda $=.91, F(3$, 27) $=.93, n s$.

\section{Investigation of the Total Number of Correct Answers According to the KIDI Dimension and Moderation with Social Support}

Considering that an effect for time was found in the total number of correct answers, as well as an effect for KIDI dimensions, we verified whether the total number of correct answers in each of the KIDI dimensions (Parenting, Health, Standards, and Principles) was moderated by the level of social support (high vs. low). For that, a multivariate analysis of variance for the repeated measures model (KIDI Dimensions) x 4 (points in time: T1; T2; T3; T4) x 2 (high social support vs. low social support) was developed. 
As expected, a main effect of time was found [Wilks' lambda $\left.=.48, F(3,26)=9,27, p<.001, \eta_{\mathrm{p}}^{2}=.52\right]$, as well as for KIDI dimensions [Wilks' lambda $=.33, F(3,26)=18.00, p<.001$, $\left.\eta_{\mathrm{p}}^{2}=.68\right]$. Nevertheless, the total number of correct answers in each KIDI dimension was not moderated by the level of social support (Wilks'lambda $=.90, F(3,26)=.96, n s)$.

\section{Discussion}

The importance of knowledge for child development is central to the quality of care provided to children during the first year of life. Note, however, that proper knowledge is not necessarily translated into maternal practices. This study shows that maternal knowledge improved over time and the mothers' perception of social support was a positive factor. That is, knowledge of child development was greater among mothers who reported greater social support. Despite limitations concerning the sample's representativeness, this is a relevant finding that can contribute to improved information on maternal cognitions among adolescent mothers facing psychosocial vulnerability.

\section{What Mothers Know}

Knowledge of infant development is an important component in the interaction established with a child, so that it is important to identify its characteristics. This study's sample, marked by psychosocial vulnerability, presented a mean percentage of total hits of $52 \%$ at $\mathrm{T} 1$. This percentage is less than those reported by other studies conducted in Brazil (Bornstein et al., 2010), revealing the poor knowledge of these mothers, which may limit the proper development of their children. Such knowledge, however, tended to improve over time $(62 \%$ hits at T4), though the questions with the highest number of misses remained incorrect at the different points in time. This information reveals, on one hand, the difficulty of the participants in assimilating competencies concerning the baby, which would change their level of knowledge. On the other hand, changes in knowledge were verified when a difference of incorrect answers was verified from $\mathrm{T} 1$ to T4. The mothers modified, for instance, their perceptions regarding the baby's needs (e.g.: Question 1) showing, as discussed in the literature, that childcare changes, at least in part, one's knowledge regarding child development (Fuligni et al., 2013; Tamis-LeMonda et al., 2002).

Both at T1 and at T4, Parenting was the domain in which a greater number of hits were observed, followed by Health, Principles, and Standards. This distribution of hits is in agreement with that reported by other studies (Bornstein et al., 1996, 2010), revealing that the Brazilian adolescent mothers addressed in this study tended to have a level of knowledge of child development that is similar to that reported in the Brazilian and international literature, which usually addresses middle-class adult mothers. Possibly, this result translates a culture that dominates Western societies (i.e., Europe, North and South Americas) in regard to child development (Bornstein et al., 1996; Luo \& Tamis Le-Monda, 2015), regardless of the social group to which one belongs.
In fact, these results reveal that knowledge concerning child development is not homogeneously acquired since the participants revealed greater facility in some of the knowledge dimensions. Therefore, in addition to a cultural pattern, these findings may also suggest the existence of a homogeneous set of information regarding practical care that is provided to children based on the international guidelines provided by the World Health Organization (Ministério de Saúde, 2011; WHO, 2011). The results reveal that health and safety practices seem to be well assimilated by the mothers. For instance, most of the participants know that a baby is supposed to have a physical at regular intervals (Question 2), or that they should not eat peanuts at 9 months of age (Question 6). Aspects linked to the child's emotional development, however, seem to be ignored by most mothers, especially during the first months of life. The mothers' better performance in the Health and Parenting dimensions may reveal the focus of care policies integrated between women and family health. These interventions seem to overvalue aspects regarding children's functional care, underestimating the caregivers' emotional and social components (e.g., gender equality), as well as the challenges inherent to raising children during the first years of life. This hypothesis is reinforced when we verify that even the dimensions in which a greater number of hits were found, those questions addressing less functional content, present a high number of misses (e.g.: Question 19: "Men are naturally awkward when they take care of babies").

The data obtained here also reveal that parental practices associated with "common sense" remain rooted in their mothers' knowledge. For instance, despite the risk of suffocation associated with the use of pillows for newborns, which is reported in various documents provided by the Brazilian Ministry of Health, most mothers still believe that "the use of pillows helps the baby sleep better" (Question 24). This was also one of the answers most frequently answered wrong in the study by Ribas et al. (2003), showing a need for public policies and interventions that focus on changing cultural practices. Note that in this aspect, social support networks can contribute to strengthening misbeliefs, hindering the acquisition of new sources of knowledge.

The results showed a lower level of knowledge at all four points in time for the Standard dimension. This lack of knowledge may create unrealistic expectations regarding child development and, consequently, frustration regarding one's parental ability, as well as a child's abilities.

\section{Time and Social Support for Maternal Knowledge of Child Development}

Time was associated with improved maternal knowledge of child development; in particular, the knowledge reported during pregnancy was significantly different from that obtained at other points in time. This change may be associated with the baby's birth and the experience of motherhood. Studies reveal that maternal knowledge tends to be associated with the child's age (Bornstein et al., 2010; Fuligni et al., 2013; Tamis-LeMonda et al., 2002). Even though little is known about this association, it may be associated with the practice 
of delivering care to a baby (Fuligni et al., 2013; TamisLeMonda et al., 2002). It is, however, important to note that better levels of knowledge concerning child development, in this sample, were not linearly transferred to the quality of maternal behavior. This result may be explained by the context of development marked by psychosocial vulnerability. Mothers with a low socioeconomic status tend to less frequently respond to a baby's signs, possibly due to multiple demands, greater levels of stress, and/or poor social support networks (Evans et al., 2008). This information reveals that, even though knowledge of child development is an important dimension of maternal behavior, personal and environmental resources influence the quality of maternal behavior. The quality of maternal behavior seems to be associated with acknowledgement of the mother-baby relationship, rather than access to information regarding care and the local service network (Guttentag et al., 2014). The authors emphasize the importance of mothers receiving detailed information on how to promote a quality relationship as a way to promote improved care. Therefore, for this knowledge to be effective, it is supposed to meet the ecological characteristics of the developmental context.

This study's results also reveal that improved knowledge was associated with the perception of social support. Social support tends to be described as a central core of the quality of maternal performance, especially among adolescent mothers (Devereux et al., 2009; Jahromi et al., 2014). Considering that social support is a multidimensional construct composed of emotional, affective and instrumental dimensions, it may be an important moderator of a mother's self-assurance regarding maternal performance, and, consequently, of a mother's assessment of knowledge concerning child development. Additionally, the main sources of information on development, parenting, and care provided to children tend to come from the family itself or people identified as trustworthy (Cochran \& Niego, 2002; Winter et al., 2012), which may explain the moderator effect of high social support, increasing knowledge on infant development over time. Previous studies (Jahromi et al., 2014) reveal that adolescent mothers tend to reveal accurate knowledge of child development, though they do not have confidence on their knowledge. The authors consider a lack of self-assurance to be associated with the age and lower education level of adolescent mothers. In this sense, a perception of greater social support would reinforce the confidence of mothers in their level of knowledge.

Formal education and income are typically described as variables associated with a better level of knowledge of child development (Bornstein et al., 2010; Ribas et al., 2003). This study's sample was characterized by low educational and income levels. A lack of formal resources to obtain knowledge of child development translates into a greater need for external resources, namely social support, which would explain the moderating role of social support found in this study. Possibly the mothers' perceptions of social support make them feel more open and confident to receive information, including information concerning child development. A lack of this moderating role between the four KIDI dimensions and level of social support reveals that social support in this sample did not favor knowledge in specific dimensions.

Postpartum depression is identified as an inhibitor of care provided to babies (Brown et al., 2012; Goodman et al., 2011; Lanzi et al., 2009). In this study, however, no association was found between maternal depression and knowledge of child development. That is, inhibited care does not accrue from lower levels of knowledge concerning infant development, since depression did not play a moderator effect. Therefore, even though the presence of depression did not interfere in the level of knowledge of child development in this sample, it does affect the quality of care provided to babies during the first year of life.

Note that postpartum depression emerges as one of the main problems associated with adolescent pregnancy (Brown et al., 2012). Adolescent mothers tend to present higher levels of depression when compared to adult mothers (Petterson \& Albers, 2001). The context of psychosocial vulnerability in which most adolescent pregnancies tend to occur and a lack of social support are the main explanations for these differences (Brown et al., 2012; Devereux et al., 2009; Petterson \& Albers, 2001). One Brazilian study reveals a prevalence of postpartum depression of $26.9 \%$ among mothers under the age of 20 (Theme, Ayers, Gama, \& Leal, 2016). International studies (Brown et al., 2012) report between 30\% and 59\%. Such a difference is explained by the different instruments used and the characteristics of the samples. Thus, the percentages found here are similar to those reported in the literature.

This study's findings enabled the identification of social and cultural aspects that ground maternal knowledge of child development, influencing the wellbeing of children. This study contributes to the identification of aspects associated with the knowledge of child development of adolescent mothers experiencing psychosocial vulnerability. Among the results found in this sample, the modification of knowledge over time stands out, possibly associated with the practice of care provided to babies and the moderating role of social support. Nonetheless, the level of knowledge was not associated with the quality of maternal behavior. This information reveals a need for interventions directed to this population intended to strengthen the relationship between parents/infant, rather than only focusing on the educational aspects of care (Guttentag et al., 2014), so that knowledge is effectively transferred to interactive practices and to the care provided to babies.

Despite the important results found here, some limitations need to be considered. Note that the sample size does not allow for the generalization of results. Nonetheless, the similarity of the results found here with those reported by other studies confirms the validity of the results. It is noteworthy that a difficult-to-access population, such as adolescent mothers, was investigated, along with the importance of social support for their knowledge of child development. The poor level of knowledge revealed by these participants and the non-association with maternal quality of behavior show a need to devise interventions directed to this population. Moreover, there is a need to discuss the socioemotional aspects of caregivers and children. Additionally, because of the moderator effect of social support on improving such knowledge, it is important to invite people significant to 
the mothers to participate in interventions in order to minimize practices that are harmful to the development of children. Future studies should investigate the main figures providing social support to adolescents and the type of social support they most frequently use to acquire knowledge of infant development and how this knowledge can be transferred to the relationship established with the baby.

\section{Referências}

Bornstein, M. H. (2013). Cross-cultural perspectives on parenting. In G. d'Ydewalle, P. Eelen, \& P. Bertelson (Eds.), International perspectives on psychological science: Vol. 2. The state of the art (pp. 359-369). Hillsdale, NJ: Lawrence Erlbaum.

Bornstein, M. H., Cote, L. R., Haynes, O. M., Hahn, C.-S., \& Park, Y. (2010). Parenting knowledge: Experiential and sociodemographic factors in European American mothers of young children. Developmental Psychology, 46(6), 1677-1693. doi:10.1037/a0020677

Bornstein, M. H., Tamis-LeMonda, C. S., \& Pascual, L., Haynes, O. M., Painter, K. M., Galperín, C. Z., \& Pêcheux, M.-G. (1996). Ideas about parenting in Argentina, France, and the United States. International Journal of Behavioral Development, 19(2), 347-367. doi:10.1177/016502549601900207

Breheny, M., \& Stephens, C. (2007). Individual responsibility and social constraint: The construction of adolescent motherhood in social scientific research. Culture, Health \& Sexuality, 9(4),333-346.doi:10.1080/13691050600975454

Brown, J. D., Harris, S. K., Woods, E. R., Buman, M. P., \& Cox, J. E. (2012). Longitudinal study of depressive symptoms and social support in adolescent mothers. Maternal and Child Health Journal, 16(4), 894-901. doi:10.1007/s10995-011-0814-9

Cochran, M., \& Niego, S. (2002). Parenting and social networks. In M. H. Bornstein (Ed.), Handbook of parenting: Vol. 4. Applied parenting (pp. 123-148). Mahwah, NJ: Lawrence Erlbaum.

Cohen, J. (1988). Statistical power analysis for the behavioral sciences (2nd ed.). Hillsdale, NJ: Lawrence Erlbaum.

Devereux, P. G., Weigel, D. J., Ballard-Reisch, D. B., Leigh, G., \& Cahoon, K. L. (2009). Immediate and longer-term connections between support and stress in pregnant/ parenting and non-pregnant/non-parenting adolescents. Child and Adolescent Social Work Journal, 26(5), 431446. doi:10.1007/s10560-009-0175-Z

Fouts, H. N., Roopnarine, J. L., Lamb, M. E., \& Evans, M. (2012). Infant social interactions with multiple caregivers: The importance of ethnicity and socioeconomic status. Journal of Cross-Cultural Psychology, 43(2), 328-348. doi:10.1177/0022022110388564
Fuligni, A. S., Brady-Smith, C., Tamis-LeMonda, C. S., Bradley, R. H., Chazan-Cohen, R., Boyce, L., \& BrooksGunn, J. (2013). Patterns of supportive mothering with 1-, 2-, and 3-year-olds by ethnicity in Early Head Start. Parenting: Science and Practice, 13(1), 44-57. doi:10.108 0/15295192.2013.732434

Goodman, S. H., Rouse, M. H., Connell, A. M., Broth, M. R., Hall, C. M., \& Heyward, D. (2011). Maternal depression and child psychopathology: A meta-analytic review. Clinical Child and Family Psychology Review, 14(1), 1-27. doi:10.1007/s10567-010-0080-1

Griep, R. H., Chor, D., Faerstein, E., Werneck, G. L., \& Lopes, C. S. (2005). Validade do constructo de escala de apoio social do Medical Outcomes Study adaptada para o português no estudo Pró-Saúde [Construct validity of the Medical Outcomes Study's social support scale adapted to Portuguese in the Pró-Saúde Study]. Cadernos de Saúde Pública, 21(3), 703-714. doi:10.1590/S0102311X2005000300004

Guttentag, C. L., Landry, S. H., Williams, J. M., Baggett, K. M., Noria, C. W., Borkowski, J. G., ... Ramey, S. L. (2014). "My Baby \& Me": Effects of an early, comprehensive parenting intervention on at-risk mothers and their children. Developmental Psychology, 50(5), 1482-1496. doi:10.1037/a0035682

Huang, K.-Y., Caughy, M. O., Genevro, J. L., \& Miller, T. L. (2005). Maternal knowledge of child development and quality of parenting among White, AfricanAmerican, and Hispanic mothers. Journal of Applied Developmental Psychology, 26(2), 149-170. doi:10.1016/j. appdev.2004.12.001

Instituto Brasileiro de Geografia e Estatística. (2012). Censo Demográfico 2010: Resultados gerais da amostra. [2010 Demographic censos: General overview] Recuperado de http://www.ibge.gov.br/home/presidencia/noticias/imprensa/ ppts/00000008473104122012315727483985.pdf

Isabella, R. A. (1993). Origins of attachment: Maternal interactive behavioracross the firstyear. ChildDevelopment, 64(2), 605-621. doi:10.1111/j.1467-8624.1993.tb02931.x

Jahromi, L. B., Guimond, A. B., Umaña-Taylor, A. J., Updegraff, K. A., \& Toomey, R. B. (2014). Family context, Mexican-origin adolescent mother's parenting knowledge, and children's subsequent developmental outcomes. Child Development, 85(2), 593-609. doi:10.1111/cdev.12160

Lanzi, R. G., Bert, S. C., Jacobs, B. K., \& Centers for the Prevention of Child Neglect. (2009). Depression among a sample of first-time adolescent and adult mothers. Journal of Child and Adolescent Psychiatric Nursing, 22(4), 194202. doi:10.1111/j.1744-6171.2009.00199.x

Luo, R., \& Tamis-LeMonda, C. S. (2015). Mothers' verbal and nonverbal strategies in relation to infants' objectdirected actions in real time and across the first three years in ethnically diverse families. Infancy, 21(1), 65-89. doi:10.1111/infa.12099 
Ministério da Saúde. Secretaria de Atenção à Saúde. Área Técnica de Saúde da Criança e Aleitamento Materno. (2011). Além da sobrevivência: Práticas integradas de atenção ao parto benéficas para a nutrição e a saúde de mães e crianças. [Beyond survival: Integrated practices of childbirth care beneficial to the nutrition and health of mothers and children ] Retrieved from http://bvsms.saude. gov.br/bvs/publicacoes/alem_sobrevivencia_atencao_ parto.pdf

O'Callaghan, M. F., Borkowski, J. G., Whitman, T. L., Maxwell, S. E., \& Keogh, D. (1999). A model of adolescent parenting: The role of cognitive readiness to parent. Journal of Research on Adolescence, 9(2), 203225. doi:10.1207/s15327795jra0902_5

Petterson, S. M., \& Albers, A. B. (2001). Effects of poverty and maternal depression on early child development. Child Development, 72(6), 1794-1813. doi:10.1111/14678624.00379

Ribas, R. C., Jr., Seidl de Moura, M. L., \& Bornstein, M. H. (2003). Socioeconomic status in Brazilian psychological research. II. Socioeconomic status and parenting knowledge. Estudos de Psicologia (Natal), 8(3), 385-392. doi:10.1590/S1413-294X2003000300005

Sanders, M. R. (2012). Development, evaluation and multinational dissemination of the triple P-positive parenting program. Annual Review of Clinical Psychology, 8, 345-379. doi:10.1146/annurev-clinpsy-032511-143104

Santos, M. F. S., Martins, F. C., \& Pasquali, L. (1999). Escala de auto-avaliação de depressão pós-parto: Estudo no Brasil[ Post-natal depression self-rating scales: Brazilian study] Revista de Psiquiatria Clinica (São Paulo), 26(2), 90-95.

Smith, P. B., \& Pederson, D. R. (1988). Maternal sensitivity and patterns of infant-mother interaction. Child Development, 59(4), 1097-1101. doi:10.2307/1130276

Tamis-LeMonda, C. S., Shannon, J., \& Spellmann, M. (2002). Low-income adolescent mothers' knowledge about domains of child development. Infant Mental Health Journal, 23(1-2), 88-103. doi:10.1002/imhj.10006

Theme Filha, M. M., Ayers, S., Gama, S. G. N., \& Leal, M. C. (2016). Factors associated with postpartum depressive symptomatology in Brazil: The Birth in Brazil National Research Study, 2011/2012. Journal of Affective Disorders, 194, 159-167. doi:10.1016/j.jad.2016.01.020

Winter, L., Morawska, A., \& Sanders, M. R. (2012). The effect of behavioral family intervention on knowledge of effective parenting strategies. Journal of Child and Family Studies, 21(6), 881-890. doi:10.1007/s10826-011-9548-y

World Health Organization. (2011). World Health Statistics. Geneva, Switzerland: WHO. Retrieved from http://www. who.int/whosis/whostat/EN_WHS2011_Full.pdf
Eva Diniz is Postdoctoral researcher at Center for Psychological Studies of At Risk Youth and Families (CepRua), Universidade Federal do Rio Grande do Sul.

Luana de Souza dos Santos is undergraduate student of Psychology at Universidade Federal de Ciências da Saúde de Porto Alegre.

Silvia Helena Koller is a Full Professor and Chair of the Center for Psychological Studies of At Risk Youth and Families (Cep-Rua), Universidade Federal do Rio Grande do Sul.

Received: Sep. 21, 2015

1st Revision: Apr. 26, 2016

2nd Revision: July 9, 2016

Approved: July 26, 2016
How to cite this article:

Diniz, E., Santos, L. S., \& Koller, S. H. (2017). Social support as moderator of knowledge about infant development within adolescent mothers. Paidéia (Ribeirão Preto), 27(68), 281-289. doi: 10.1590/1982-43272768201705 